\title{
Prenatal Exposure to Maternal Cigarette Smoke and Offspring Risk of Excess Weight Is Independent of Both Birth Weight and Catch-Up Growth
}

\author{
Jonathan Gravel,, ${ }^{1,2}$ Beth Potter, ${ }^{2}$ and Lise Dubois ${ }^{1,2}$ \\ ${ }^{1}$ Institute of Population Health, University of Ottawa, Ottawa, ON, Canada K1N 6N5 \\ ${ }^{2}$ Department of Epidemiology and Community Medicine, Faculty of Medicine, University of Ottawa, Ottawa, ON, Canada K1H $8 M S$ \\ Correspondence should be addressed to Jonathan Gravel; jgravel@analysisgroup.com
}

Received 7 June 2012; Accepted 3 July 2012

Academic Editors: H. B. Bueno-de-Mesquita and J. W. R. Twisk

Copyright ( 2013 Jonathan Gravel et al. This is an open access article distributed under the Creative Commons Attribution License, which permits unrestricted use, distribution, and reproduction in any medium, provided the original work is properly cited.

\begin{abstract}
Prenatal exposure to maternal cigarette smoke (PEMCS) is one of the most common insults to the developing fetus and has consistently emerged as an important risk factor for excess weight in the offspring. However, no consensus exists on the mechanism of action or duration of impact. This study seeks to further examine the role of PEMCS on overweight status of children up to age 10. Mother and child pairs $(n=1183)$ were analysed from the Québec Longitudinal Study of Child Development (QLSCD) (1998-2010). Multivariable logistic regression models were used to control for confounders and assess mediation. PEMCS was associated with overweight status at age 10 (OR: 1.70; 95\% CI: 1.20-2.43) after adjustment for early life exposures and childhood behaviours. This relationship remained robust after adjustment for birth weight and catch-up growth. Other significant predictors included APGAR score, mother's immigrant and weight status, family type and child energy intake. The elevated risk of excess weight among the offspring of smoking mothers was not accounted for by other known determinants, and PEMCS appears to play a role independent of birth weight and catch-up growth. Our research suggests that young mothers may be an important audience for targeting preventive strategies.
\end{abstract}

\section{Introduction}

Concern is mounting over the increase in prevalence and severity of overweight and obesity in children worldwide. Increases in overweight and obesity rates have been observed among both sexes, and across all socioeconomic groups with the strongest and most substantial increases in the developed world $[1,2]$. Canada is among the countries with the highest prevalence of both adult and child overweight and obesity worldwide $[3,4]$. The Canadian Health Measures Survey reported that approximately $17 \%$ and $6 \%$ of Canadian children aged 6- to 18-years are overweight and obese, respectively [4]. Obesity is associated with not only a wide range of adverse physical health outcomes with lifelong consequences [5], but also with negative psychological and social outcomes [6]. An important area of research aims to identify causal factors for excess weight that operate early in life to inform preventative strategies aimed at reducing future morbidity and mortality.

Childhood excess weight is ultimately a result of an energy imbalance between intake and expenditure [7], but the upstream biological mechanisms and the heightened susceptibility of certain individuals to this imbalance are not well understood [8]. Intrauterine life may be a critical period for the development of childhood excess weight. According to the developmental origins of adult disease hypothesis (the "Barker Hypothesis"), adverse influences early in development can result in permanent changes in physiology and metabolism that in turn lead to increased disease risk in later life $[9,10]$. Specifically, the current model hypothesizes that these intrauterine events act through processes of developmental plasticity or epigenetic modifications to alter the development of the fetus to an extent that they affect its capacity to cope with the environment of postnatal life. 
Prenatal exposure to maternal cigarette smoking (PEMCS) is one of the most common insults to intrauterine life [11]; in Canada, the estimated prevalence of smoking at any time during the third trimester of pregnancy remains above $10 \%$ [12]. Smoking during pregnancy is associated with a wide range of adverse fetal, obstetrical, and developmental outcomes [13]. While PEMCS has consistently emerged as an important risk factor for excess weight among offspring $[14,15]$, many studies have been unable to control for important social factors. Smoking during pregnancy has been associated with lower income and education, higher body weight of the mother, and a lower probability of breastfeeding [16], any of which may confound the association between PEMCS and overweight among offspring. Moreover, there is evidence that PEMCS may cause fetal growth restriction [15], and it has been associated with lower birth weight [17]. Children of smoking mothers may experience "catch-up growth" in the first months of life [18]. In turn, low birth weight and catch-up growth have both been associated with excess weight in infancy [19]. Thus, low birth weight and rapid catch-up growth may mediate the association between PEMCS and offspring excess weight (i.e., they may be intermediate variables on the causal pathway). Despite this, most studies of this association have adjusted for birth weight as a confounder and have neglected catch-up growth altogether. The primary objective of this study was to investigate the association between PEMCS and excess weight among offspring in a large population-based sample while controlling for a wide range of social and biological factors. The secondary objective was to examine the possible mediation of the association between PEMCS and excess weight by birth weight and catch-up growth.

\section{Methods}

2.1. Study Sample. The Québec Longitudinal Study of Child Development (QLSCD) is a prospective cohort study conducted by Santé Québec, a division of the Québec Institute of Statistics (http://www.iamillbe.stat.gouv.qc.ca/default_an .htm). The study seeks to examine the influence of a wide range of familial, social and biological factors on child development, including health, cognitive ability, and behaviour. At the onset of the study, the province of Québec had a population of just over 7.5 million and about 70000 births per year. A representative sample $(n=2120 ; 49 \%$ female $)$ of children born in Québec in 1998 were recruited through the Master Birth Registry of the Ministry of Health and Social Services of Québec. The study used a stratified random sampling design. The sample was selected within strata that were based on (1) public health geographic regions, (2) birth rates, and (3) the ratio of males to females. Children born throughout the year were recruited to minimize any effect of seasonality. Exclusions from participation included nonsingleton births, children born with major diseases, and those who died before reaching 5 months of age. Followup is ongoing.

The QLSCD collects information about both children and their parents using structured self-completed questionnaires and face-to-face interviews with mothers and fathers (http:// www.iamillbe.stat.gouv.qc.ca/outils_collecte_an.htm). From five months to eight years of age, data collection occurred annually but is now collected biannually as to minimize respondent burden. During each data collection period, participating families and interviewers signed a consent form. The consent form and study methods have been approved by the Ethics Committee of Santé Québec.

2.2. Outcome Ascertainment. Childhood weight status at ten years of age was the outcome of interest. Height (in meters) and weight (in kilograms) were measured by trained staff at the child's place of residence, using a detailed protocol and standard instruments (standard scale and measuring tape). Measurements falling between two major units were rounded down. Children were classified as being: "underweight/normal weight" or "overweight/obese" using the sexand age-specific BMI cut-offs defined by the International Obesity Task Force (IOTF) [20]. These cut-offs for 2- to 18year-olds are based on six nationally representative surveys from Brazil, Great Britain, Hong Kong, the Netherlands, Singapore, and the United States and are an extrapolation of the World Health Organization's definitions of overweight $\left(B M I \geq 25 \mathrm{~kg} / \mathrm{m}^{2}\right)$ and obesity $\left(\mathrm{BMI} \geq 30 \mathrm{~kg} / \mathrm{m}^{2}\right)$ at 18 years of age. As standard cutoffs used in the field of childhood obesity research, they allow for both interprovincial and international comparisons [21].

\subsection{Exposure Ascertainment}

2.3.1. Prenatal Exposure to Maternal Cigarette Smoking (PEMCS). The main predictor for the analysis was whether a child respondent was exposed to tobacco smoke in-utero. This variable was self-reported by the mother when the child was 5 months old.

2.3.2. Birth Weight. The study team received legal access to all participating families' medical records for a period of 90 days after the mothers signed an authorization form created by the Ministry of Health and Social Services. Birth weight was extracted from each child's delivery record from the birth hospital and recorded as a continuous variable. This variable was then categorized based on standard and clinically meaningful cut-points for analyses: low birth weight $(<2.5 \mathrm{~kg})$, normal birth weight $(\geq 2.5$ and $\leq 4 \mathrm{~kg})$, and high birth weight $(>4 \mathrm{~kg})$.

2.3.3. Catch-Up Growth. Catch-up growth was derived as the difference between the mother-reported weight of the child at 5 months of age and the birth weight obtained from medical records. The continuous catch-up growth variable was converted into tertiles for analysis.

2.4. Covariates. Potential predictors of childhood overweight that were identified from published literature and available in the QLSCD database were considered for inclusion in final models. These variables included those related to birth and early life factors (whether the birth was premature, 
the birth rank, the sex, and APGAR score of the baby, whether the baby suffered from a chronic disease at 5 months, and the duration of breastfeeding), maternal characteristics (age at child's birth, highest level of education, immigrant status, postnatal smoking habits, and weight status), child behaviour lifestyle factors (energy intake, relative physical activity, and sedentary behaviour), and family demographic and socioeconomic factors (household income, single-parent or two-parent home, and geographic living area). Covariate data were obtained from different cycles of the longitudinal study, based on data collection time points and response rates at each cycle. Data from the cycle deemed most epidemiologically relevant for each covariate were used whenever possible.

2.5. Analyses. All statistical analyses were conducted using SAS version 9.2 (SAS Institute; Cary, NC). The statistical significance level for all analyses was set at an alpha value of 0.05 . The Chi-squared test of independence and univariate logistic regression was used to examine crude associations between the outcome and main predictor variables (including possible mediating variables), between the outcome and covariates, and between the main predictor variables and covariates.

Automated stepwise logistic regression was used to create final models with the entry value set at 0.20 and retention value set at 0.05 for all models. The main predictor of interest (PEMCS) was forced into all models. Candidate covariates entered in automated regression models were chosen based on an association with the main predictor, an association with the outcome or based on an a priori decision stemming from a consistent association in the literature. The final model included the following covariates: sex, APGAR score, duration of exclusive breastfeeding, immigrant status of the mother, mother's BMI, energy intake, physical activity, sedentary behaviour, family income, and family type. Once the base model was created (model 1), the potential mediating effects of birth weight and/or catch-up growth on the relationship between the main predictor (PEMCS) and outcome (overweight status) were assessed qualitatively using model 1 with the addition of only birth weight (model 2); the addition of only catch-up growth (model 3); and the addition of birth weight and catch-up growth simultaneously (model 4). Qualitative mediation was assessed through examination of the beta estimates of PEMCS of models 2, 3, and 4 and comparing them to the baseline beta of model 1. Evidence of partial mediation was defined as a meaningful change in the odds ratio of the main predictor. Full mediation was defined as complete replacement of the effect of PEMCS by that of birth weight and/or catch-up growth. This definition is in line with the Baron and Kenny as well as the McArthur approach to assess mediation [22]. Model fit was assessed using the Hosmer and Lemeshow Goodness of Fit Test and outliers were assessed using index and DFBETA plots.

\section{Results}

3.1. Descriptive. Of 2120 family participants recruited into the QLSCD in 1998, 1280 children were still being followed at age 10 , and 1183 (55.8\% of the original sample) had no itemmissing data for key variables (PEMCS, measured height and weight, birth weight, and catch-up growth). Children included in this analysis were similar to those excluded on available variables (data not shown).

Using the IOTF definitions for overweight, $25 \%$ of respondent children included in the analysis were overweight at age 10, with a mean BMI of 16.87 and 22.88 for the normal weight and overweight groups, respectively. Table 1 presents the descriptive characteristics of the children included in this study according to their overweight or obesity status. In comparison to others, overweight children were more likely to have been born premature $(P=0.0287)$ and to have had a high risk APGAR score $(P=0.0086)$. Mothers of overweight children were more likely to be overweight themselves $(P<$ 0.0001 ). Being overweight at 10 years of age was significantly associated with being in the highest quintile of energy intake $(P<0.0001)$. Overall, families with an overweight child tended to have a lower household income $(P=0.0015)$ and were less likely to have a single-parent family structure $(P=0.0019)$.

At the bivariable level, PEMCS was significantly and positively associated with being overweight at age $10(P=$ 0.003 ). As described above, PEMCS was positively associated with both low birth weight and catch-up growth; however, neither low birth weight nor catch-up growth was statistically significantly associated with being overweight at age 10, although the association did approach statistical significance $(P=0.0851)$.

From the multivariable logistic regression analysis, the adjusted association between PEMCS and overweight at age 10 was positive and statistically significant (OR: 1.70; 95\% CI: 1.20-2.43) (Table 2). Additional significant predictors in the final multivariable model included APGAR score, maternal immigrant status, maternal weight status, family type, and energy intake. The strongest predictor of overweight status at age 10 was the weight status of the mother (OR: 2.90; 95\% CI: 2.10-3.99) (Table 2).

In the multivariable examination of possible mediation of the relationship between PEMCS and overweight status at age 10 (Table 3), the addition of birth weight to the base model (model 1) had no meaningful impact the estimated odds ratio for PEMCS as a predictor of childhood overweight. A similar nonmeaningful change in magnitude occurred after the addition of catch-up growth to the model. When both birth weight and catch-up growth were added to the model, the point estimate changed again only very slightly.

\section{Discussion}

Despite the well-documented deleterious effects of PEMCS, it remains one of the most common insults to the developing fetus. The epidemiological evidence demonstrating an association between PEMCS and increased risk for excess weight is strong and consistent, but the underlying mechanisms remain largely speculative. Our study sought to evaluate the relationship between PEMCS and the risk of overweight or obesity of children and to examine the possible mediating 
TABLE 1: Descriptive characteristics of children included in the analysis by overweight or obesity status at age $10(n=1183)$.

\begin{tabular}{|c|c|c|c|}
\hline Cycle collected & & $\begin{array}{l}\text { Overweight or obese children } \\
\qquad(n=305)\end{array}$ & $\begin{array}{l}\text { Normal weight children } \\
\qquad(n=878)\end{array}$ \\
\hline & Birth and Early Life & & \\
\hline \multirow[t]{3}{*}{5 months } & PEMCS & & \\
\hline & No & $209(68.5 \%)$ & $692(78.8 \%)^{*}$ \\
\hline & Yes & $96(31.5 \%)$ & $186(21.2 \%)$ \\
\hline \multirow[t]{4}{*}{ Medical records } & Birth weight & & \\
\hline & $>4 \mathrm{~kg}$ & $45(14.9 \%)$ & $91(10.3 \%)$ \\
\hline & $\leq 2.5 \mathrm{~kg}$ and $\leq 4 \mathrm{~kg}$ & $249(81.8 \%)$ & $762(86.8 \%)$ \\
\hline & $<2.5 \mathrm{~kg}$ & $11(3.3 \%)$ & $25(2.9 \%)$ \\
\hline \multirow[t]{3}{*}{ Medical records } & Premature birth ( $<37$ weeks) & & \\
\hline & No & $285(93.4 \%)$ & $846(96.4 \%)^{*}$ \\
\hline & Yes & $20(6.6 \%)$ & $32(3.6 \%)$ \\
\hline \multirow[t]{3}{*}{ Medical records } & APGAR score ${ }^{a}$ & & \\
\hline & Other & $265(87.0 \%)$ & $809(92.1 \%)^{*}$ \\
\hline & High risk (0-6) & $40(13.0 \%)$ & $69(7.9 \%)$ \\
\hline \multirow[t]{4}{*}{ Medical records } & Birth rank & & \\
\hline & First & $126(41.4 \%)$ & $407(46.3 \%)$ \\
\hline & Second & $130(42.7 \%)$ & $333(37.9 \%)$ \\
\hline & $\geq$ Third & $48(15.9 \%)$ & $139(15.8 \%)$ \\
\hline \multirow[t]{3}{*}{ Medical records } & Sex & & \\
\hline & Female & $160(52.3 \%)$ & $467(53.2 \%)$ \\
\hline & Male & $145(47.7 \%)$ & $411(46.8 \%)$ \\
\hline \multirow[t]{4}{*}{5 months } & Catch-up growth & & \\
\hline & 1st tertile & $101(33.1 \%)$ & $316(36.0 \%)$ \\
\hline & 2nd tertile & $101(33.1 \%)$ & $310(35.3 \%)$ \\
\hline & 3rd tertile & $103(33.8 \%)$ & $252(28.7 \%)$ \\
\hline \multirow{3}{*}{5 months } & Chronic disease $^{\mathrm{b}}$ & & \\
\hline & No & $261(85.4 \%)$ & $751(85.6 \%)$ \\
\hline & Yes & $44(14.6 \%)$ & $127(14.4 \%)$ \\
\hline \multirow[t]{5}{*}{17 months } & Duration of breastfeeding (exclusive) & & \\
\hline & $\geq 3$ months & $86(28.2 \%)$ & $234(26.7 \%)$ \\
\hline & Other & $133(43.7 \%)$ & $421(47.9 \%)$ \\
\hline & Never & $86(28.1 \%)$ & $223(25.4 \%)$ \\
\hline & Maternal & & \\
\hline \multirow[t]{5}{*}{5 months } & Age at child's birth (years) & & \\
\hline & $\leq 29$ & $60(19.5 \%)$ & $185(21.1 \%)$ \\
\hline & $30-34$ & $92(30.2 \%)$ & $285(32.5 \%)$ \\
\hline & $35-39$ & $108(35.4 \%)$ & $288(32.8 \%)$ \\
\hline & $\geq 40$ & $45(14.9 \%)$ & $120(13.6 \%)$ \\
\hline \multirow[t]{3}{*}{10 years } & Level of education & & \\
\hline & $\geq$ Secondary school diploma & $270(88.4 \%)$ & $786(89.5 \%)$ \\
\hline & $<$ Secondary school diploma & $35(11.6 \%)$ & $92(10.5 \%)$ \\
\hline \multirow[t]{3}{*}{10 years } & Immigrant Status & & \\
\hline & Nonimmigrant & $279(91.4 \%)$ & $818(93.2 \%)$ \\
\hline & Immigrant & $26(8.6 \%)$ & $60(6.8 \%)$ \\
\hline \multirow[t]{3}{*}{10 years } & Postnatal smoking habits & & \\
\hline & Non-smoker & $229(75.1 \%)$ & $751(85.6 \%)^{*}$ \\
\hline & Smoker & $76(24.9 \%)$ & $127(14.4 \%)$ \\
\hline
\end{tabular}


TABLE 1: Continued.

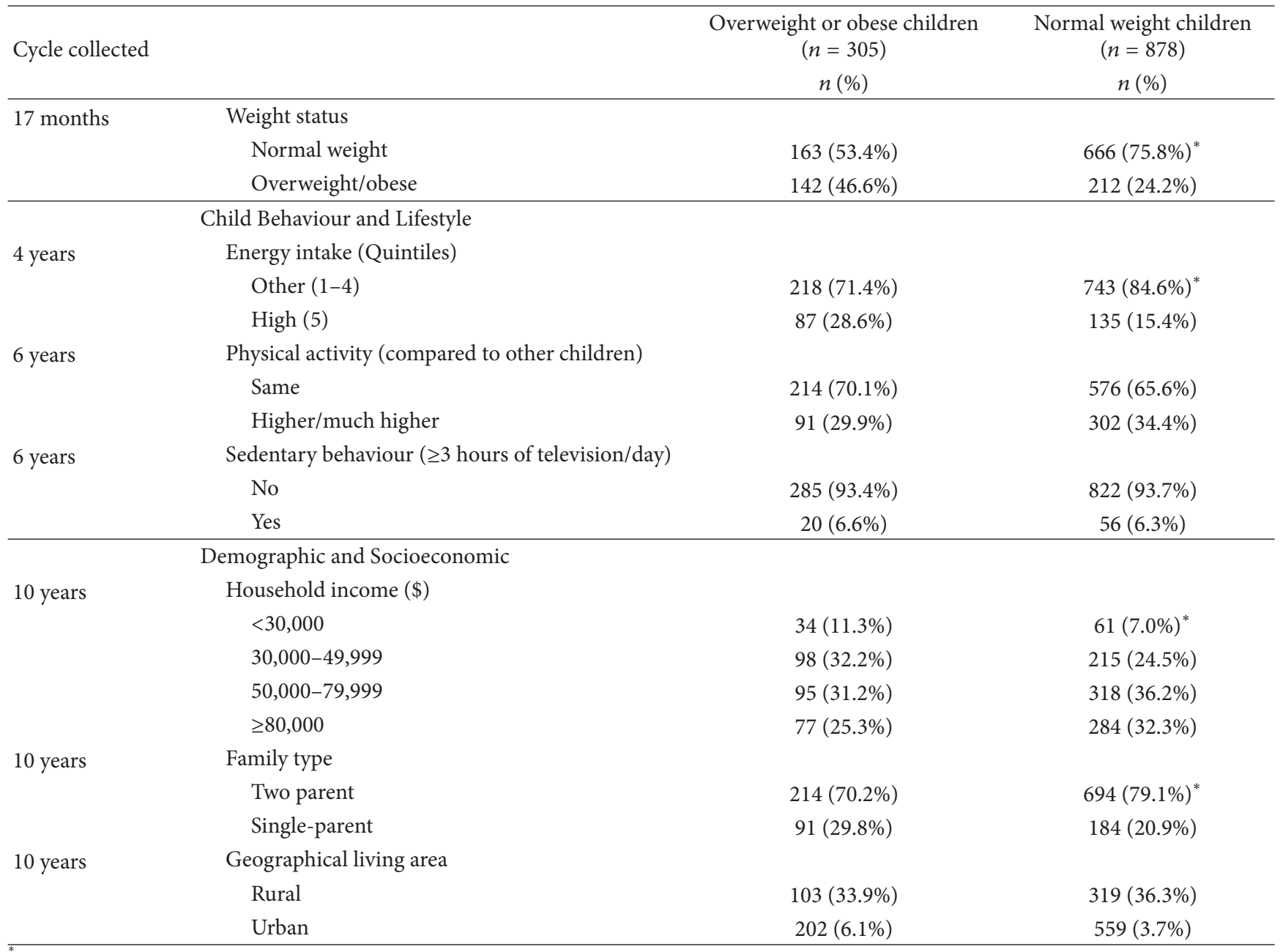

"Denotes a statistically significant difference of covariate proportion between overweight and nonoverweight participants $(P<0.05)$.

${ }^{a}$ A crude scale $(0-10)$ of assessing a baby's health immediately after birth, by scoring points for heart rate, breathing, skin colour, tone, and the baby's reactions.

${ }^{\mathrm{b}}$ Excludes allergies but includes asthma.

Source: Québec Longitudinal Study of Child Development (QLSCD) 1998-2010, Québec Institute of Statistics.

TABLE 2: Odds ratios (or) and 95\% confidence intervals (CI) of PEMCS and relevant covariates included in the final model on overweight status (IOTF) at age 10 .

\begin{tabular}{|c|c|c|c|c|c|}
\hline Covariate & Category & Unadjusted OR & $95 \% \mathrm{CI}$ & Adjusted $\mathrm{OR}^{\mathrm{a}}$ & $95 \% \mathrm{CI}$ \\
\hline \multirow{2}{*}{ PEMCS } & No & 1.00 & - & 1.00 & - \\
\hline & Yes & 1.71 & {$[1.23,2.19]$} & 1.70 & {$[1.20,2.43]$} \\
\hline \multirow{2}{*}{ APGAR score } & Other & 1.00 & - & 1.00 & - \\
\hline & High risk & 1.75 & {$[1.15-2.66]$} & 1.80 & {$[1.09,2.98]$} \\
\hline \multirow{2}{*}{ Mother's immigrant status } & Non immigrant & 1.00 & - & 1.00 & - \\
\hline & Immigrant & 1.29 & {$[0.80,2.08]$} & 1.80 & {$[1.00,3.24]$} \\
\hline \multirow{2}{*}{ Mother's weight status } & Normal weight & 1.00 & & 1.00 & \\
\hline & Overweight & 2.71 & {$[2.06,3.58]$} & 2.89 & {$[2.10,3.99]$} \\
\hline \multirow{2}{*}{ Family type } & Two parent & 1.00 & - & 1.00 & - \\
\hline & Single-parent & 1.60 & {$[1.15,2.22]$} & 1.62 & {$[1.08,2.45]$} \\
\hline \multirow{2}{*}{ Energy intake } & Other (1-4) & 1.00 & - & 1.00 & - \\
\hline & High (5) & 2.19 & {$[1.57,3.05]$} & 2.17 & {$[1.51,3.13]$} \\
\hline
\end{tabular}

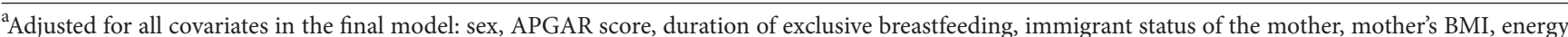
intake, physical activity, sedentary behaviour, family income, and family type.

Source: Québec Longitudinal Study of Child Development (QLSCD) 1998-2010, Québec Institute of Statistics. 
TABLE 3: The Odds ratios (OR) and 95\% confidence intervals (CI) for the association between overweight (IOTF) at age 10 and PEMCS with adjustment for possible mediators.

\begin{tabular}{|c|c|c|c|c|}
\hline & $\begin{array}{l}\text { Base model } \\
(\operatorname{model} 1)^{\mathrm{a}}\end{array}$ & $\begin{array}{l}\text { Adjusted for birth } \\
\text { weight (model } 2)^{b}\end{array}$ & $\begin{array}{l}\text { Adjusted for catch-up } \\
\text { growth (model 3) }\end{array}$ & $\begin{array}{l}\text { Adjusted for both } \\
\quad(\text { model } 4)^{\mathrm{d}}\end{array}$ \\
\hline & OR $(95 \% \mathrm{CI})$ & OR $(95 \% \mathrm{CI})$ & OR $(95 \% \mathrm{CI})$ & OR $(95 \% \mathrm{CI})$ \\
\hline \multicolumn{5}{|c|}{ PEMCS } \\
\hline No & 1.00 & 1.00 & 1.00 & 1.00 \\
\hline Yes & $1.70(1.19-2.43)$ & $1.76(1.23-2.51)$ & $1.64(1.15-2.33)$ & $1.73(1.21,2.48)$ \\
\hline \multicolumn{5}{|c|}{$\begin{array}{l}\text { aAdjusted for: sex, APGAR score, duration of exclusive breastfeeding, immigrant status of the mother, mother's BMI, energy intake, level of physical activit } \\
\text { level of sedentary behaviour, family income, and family type. }\end{array}$} \\
\hline \multicolumn{5}{|c|}{$\begin{array}{l}{ }^{b} \text { Adjusted for all variables listed for model } 1 \text { with the addition of birth weight. } \\
{ }^{c} \text { Adjusted for all variables listed for model } 1 \text { with the addition of catch-up growth. }\end{array}$} \\
\hline \multicolumn{5}{|c|}{ d Adjusted for all variables listed for model 1 with the addition of birth weight and catch-up growth. } \\
\hline
\end{tabular}

role of birth weight and catch-up growth. Since PEMCS has consistently emerged as an important risk factor for low birth weight, it has been proposed as a possible mediator of the PEMCS-overweight relationship. Babies of low birth weight often experience a rapid catch-up growth phase during infancy or childhood, and this has been proposed as a potential pathway to link PEMCS to excess weight. To our knowledge, our study is the first to empirically investigate the hypothesis of a combined mediation effect of low birth weight and catch-up growth.

PEMCS was found to be a significant and independent predictor of childhood overweight at 10 years of age among Québec children even after adjusting for several important social and biological factors. Although our study demonstrated a positive association between PEMCS and both low birth weight and catch-up growth, neither potential mediator was related to overweight at age 10 in our sample. Furthermore, no attenuation of the PEMCS-overweight status association occurred when birth weight, catch-up growth, or both were included in the multivariable model. Thus, our findings do not support the hypothesis that low birth weight and/or catch-up growth are mediators of the PEMCSchildhood overweight relationship.

That PEMCS remained a significant risk factor for excess childhood adiposity independent of a wide range of common correlates of both the exposure, and the outcome supports the conclusions of recent systematic reviews $[14,15]$. The fact that this association held strong after adjustment for birth weight supports findings from Beyerlein and colleagues $[23,24]$ and previous studies that did not assess this association directly but controlled for low birth weight in multivariable analyses $[25,26]$. Our results are also supported by rodent work showing that fetal nicotine exposure can cause an increase in body weight with no difference in mean birth weight between the exposed and the unexposed [27, 28]. However, several studies have reported low birth weight as a mediator of the relationship between PEMCS and overweight status [29, 30]. The finding that the association of PEMCS and excess weight were unchanged after adjustment for a measure of catch-up growth has not, to our knowledge, been described in previous research.
Given that we found no strong evidence of mediation involving birth weight or catch-up growth, the mechanism through which PEMCS may lead to excess weight among offspring remains unclear. Possible alternative mechanisms exist at the hypothalamic or fat cell level. These include altered appetite behaviour due to alterations of cholinergic neurotransmitter systems [31] or even changes in food digestion efficiency [32]. There is some empirical support for the role of inappropriate setting of systemic hypothalamic control of both appetite and energy expenditure [33]. Fetal exposure to nicotine has also been shown to cause abnormal fat cell proliferation, differentiation, and synaptic activity in both the brain and peripheral autonomic pathways [34]. Some have shown that, even at birth, infants born to smoking mothers have a preserved ponderal index (weight for length) [35] with relatively more body fat mass [36]. Most of this mechanistic evidence is from ex vivo research and from animal models. Among the challenges in drawing conclusions from this evidence, these studies have concentrated on nicotine, which is only one of the thousands of chemicals found in a commercial cigarette.

It may be argued that the relationship between PEMCS and excess weight in offspring is not causal at all, but due to an unaccounted confounding factor, such as postnatal exposure to smoking. However, previous studies have suggested that paternal smoking can explain little [37] or none [38] of the association between PEMCS and offspring overweight, which refutes this idea. Furthermore, in a recent Australian study, the prevalence of overweight among children whose mothers smoked before and/or after pregnancy but not during pregnancy was similar to those who had never smoked at all [39].

Our findings need to be considered while acknowledging certain limitations. The primary outcome of this study was weight status of children based on established international cut-offs for BMI. The limitations of BMI are very well known [40]; however, BMI remains the most practical and most commonly used measure to screen overweight and obese children. In our study, BMI was derived from objectively measured heights and weights by trained staff, which has been shown to improve BMI as an indicator of overall 
adiposity [41]. The exposure of interest, PEMCS, relied on maternal self-report of smoking behaviors with no biochemical validation. Because smoking during pregnancy is a complex behaviour with both daily fluctuations and changes over the course of pregnancy, quantifying tobacco exposure is a challenge. Different patterns of timing, duration, type, and quantity of maternal smoking may alter the effect on weight outcomes. However, misclassification of smoking would likely bias the estimated association between PEMCS and excess weight towards the null. Despite the aforementioned limitations, this study included a large longitudinal sample of children. We were able to take into consideration a wide range of important child, mother, and family sociodemographic characteristics to account for potentially confounding variables, including measures of both energy intake and physical activity.

The developmental origins of excess weight and the notion of priming chronic disease early in life are complex. Prospective longitudinal studies with repeated measures of heights and weights are needed to further quantify and compare the effects of early life risks. Regardless of the mechanism of action, if the evidence continues to support a causal role for PEMCS in contributing to childhood overweight and obesity, this represents an important opportunity for prevention. PEMCS is a key modifiable risk factor for a number of adverse pregnancy outcomes, highlighting its importance as a target for preventive action. Given the tracking of relative weight status from childhood through to adult life, targeting overweight and obesity early in life in turn may have lifelong impacts on physical health and quality of life.

\section{Acknowledgments}

Data were collected by the Québec Institute of Statistics for the Longitudinal Study of the Child Development of Québec. The authors would also like to acknowledge both Megan Carter and Dr. Tim Ramsay. J. Gravel was a recipient of a Frederick Banting and Charles Best Canada Graduate Scholarship from the Canadian Institute of Health Research (CIHR) at the time this work was done.

\section{References}

[1] T. Lobstein, L. Baur, and R. Uauy, "Obesity in children and young people: a crisis in public health," Obesity Reviews, vol. 5, supplement 1, pp. 4-104, 2004.

[2] M. M. Finucane, G. A. Stevens, M. J. Cowan et al., "National, regional, and global trends in body-mass index since 1980: systematic analysis of health examination surveys and epidemiological studies with 960 country-years and 9.1 million participants," The Lancet, vol. 377, no. 9765, pp. 557-567, 2011.

[3] M. S. Tremblay, M. Shields, M. Laviolette, C. L. Craig, I. Janssen, and S. C. Gorber, "Fitness of Canadian children and youth: results from the 2007-2009 Canadian Health Measures Survey.", Health Reports, vol. 21, no. 1, pp. 7-20, 2010.

[4] D. T. Finegood, T. D. N. Merth, and H. Rutter, "Implications of the foresight obesity system map for solutions to childhood obesity," Obesity, vol. 18, supplement 1, pp. S13-S16, 2010.
[5] J. J. Reilly, E. Methven, Z. C. McDowell et al., "Health consequences of obesity," Archives of Disease in Childhood, vol. 88, no. 9, pp. 748-752, 2003.

[6] R. M. Puhl and K. D. Brownell, "Psychosocial origins of obesity stigma: toward changing a powerful and pervasive bias," Obesity Reviews, vol. 4, no. 4, pp. 213-227, 2003.

[7] C. O. Stubbs and A. J. Lee, "The obesity epidemic: both energy intake and physical activity contribute," Medical Journal of Australia, vol. 181, no. 9, pp. 489-491, 2004.

[8] M. Selassie and A. C. Sinha, "The epidemiology and aetiology of obesity: a global challenge," Best Practice and Research, vol. 25, no. 1, pp. 1-9, 2011.

[9] E. Oken and M. W. Gillman, "Fetal origins of obesity," Obesity Research, vol. 11, no. 4, pp. 496-506, 2003.

[10] W. Y. Jiang, W. Han, and Z. X. Li, "Evidence and mechanisms of fetal origins of adult diseases," Beijing Da Xue Xue Bao, vol. 39, no. 1, pp. 96-100, 2007.

[11] A. Romo, R. Carceller, and J. Tobajas, "Intrauterine growth retardation (IUGR): epidemiology and etiology," Pediatric Endocrinology Reviews, vol. 6, supplement 3, pp. 332-336, 2009.

[12] B. Al-Sahab, M. Saqib, G. Hauser, and H. Tamim, "Prevalence of smoking during pregnancy and associated risk factors among Canadian women: a national survey," BMC Pregnancy and Childbirth, vol. 10, p. 24, 2010.

[13] R. L. Andres and M. C. Day, "Perinatal complications associated with maternal tobacco use," Seminars in Neonatology, vol. 5, no. 3, pp. 231-241, 2000.

[14] E. Oken, E. B. Levitan, and M. W. Gillman, "Maternal smoking during pregnancy and child overweight: systematic review and meta-analysis," International Journal of Obesity, vol. 32, no. 2, pp. 201-210, 2008.

[15] T. Ino, "Maternal smoking during pregnancy and offspring obesity: meta-analysis," Pediatrics International, vol. 52, no. 1, pp. 94-99, 2010.

[16] L. Dubois and M. Girard, "Early determinants of overweight at 4.5 years in a population-based longitudinal study," International Journal of Obesity, vol. 30, no. 4, pp. 610-617, 2006.

[17] S. J. Ventura, B. E. Hamilton, T. J. Mathews, and A. Chandra, "Trends and variations in smoking during pregnancy and low birth weight: evidence from the birth certificate, 1990-2000," Pediatrics, vol. 111, no. 5, pp. 1176-1180, 2003.

[18] P. O. A. Monteiro and C. G. Victora, "Rapid growth in infancy and childhood and obesity in later life-a systematic review," Obesity Reviews, vol. 6, no. 2, pp. 143-154, 2005.

[19] K. K. L. Ong, M. L. Ahmed, D. B. Dunger, P. M. Emmett, and M. A. Preece, "Association between postnatal catch-up growth and obesity in childhood: prospective cohort study," British Medical Journal, vol. 320, no. 7240, pp. 967-971, 2000.

[20] T. J. Cole, M. C. Bellizzi, K. M. Flegal, and W. H. Dietz, "Establishing a standard definition for child overweight and obesity worldwide: international survey," British Medical Journal, vol. 320, no. 7244, pp. 1240-1243, 2000.

[21] W. H. Dietz and T. N. Robinson, "Use of the body mass index (BMI) as a measure of overweight in children and adolescents," Journal of Pediatrics, vol. 132, no. 2, pp. 191-193, 1998.

[22] H. C. Kraemer, M. Kiernan, M. Essex, and D. J. Kupfer, "How and why criteria defining moderators and mediators differ between the Baron \& Kenny and MacArthur approaches," Health Psychology, vol. 27, supplement 2, pp. S101-S108, 2008.

[23] A. Beyerlein, S. Rückinger, A. M. Toschke, A. Schaffrath Rosario, and R. Von Kries, "Is low birth weight in the causal 
pathway of the association between maternal smoking in pregnancy and higher BMI in the offspring?" European Journal of Epidemiology, vol. 26, no. 5, pp. 413-420, 2011.

[24] S. Rückinger, A. Beyerlein, G. Jacobsen, R. von Kries, and T. Vik, "Growth in utero and body mass index at age 5 years in children of smoking and non-smoking mothers," Early Human Development, vol. 86, no. 12, pp. 773-777, 2010.

[25] M. Adams, A. M. N. Andersen, P. K. Andersen et al., "Sostrup statement on low birthweight," International Journal of Epidemiology, vol. 32, no. 5, pp. 884-885, 2003.

[26] R. Von Kries, A. M. Toschke, B. Koletzko, and W. Slikker Jr, "Maternal smoking during pregnancy and childhood obesity," American Journal of Epidemiology, vol. 156, no. 10, pp. 954-961, 2002.

[27] W. J. A. Chen and R. B. Kelly, "Effect of prenatal or perinatal nicotine exposure on neonatal thyroid status and offspring growth in rats," Life Sciences, vol. 76, no. 11, pp. 1249-1258, 2005.

[28] Y. J. Gao, A. C. Holloway, Z. H. Zeng et al., "Prenatal exposure to nicotine causes postnatal obesity and altered perivascular adipose tissue function," Obesity Research, vol. 13, no. 4, pp. 687-692, 2005.

[29] A. J. Sharma, M. E. Cogswell, and R. Li, "Dose-response associations between maternal smoking during pregnancy and subsequent childhood obesity: effect modification by maternal race/ethnicity in a low-income US cohort," American Journal of Epidemiology, vol. 168, no. 9, pp. 995-1007, 2008.

[30] K. Suzuki, D. Ando, M. Sato, T. Tanaka, N. Kondo, and Z. Yamagata, "The association between maternal smoking during pregnancy and childhood obesity persists to the age of 9-10 years," Journal of Epidemiology, vol. 19, no. 3, pp. 136-142, 2009.

[31] E. D. Levin, A. Wilkerson, J. P. Jones, N. Channelle Christopher, and S. J. Briggs, "Prenatal nicotine effects on memory in rats: pharmacological and behavioral challenges," Developmental Brain Research, vol. 97, no. 2, pp. 207-215, 1996.

[32] Y. J. Gao, A. C. Holloway, Z. H. Zeng et al., "Prenatal exposure to nicotine causes postnatal obesity and altered perivascular adipose tissue function," Obesity Research, vol. 13, no. 4, pp. 687-692, 2005.

[33] G. P. Ravelli, Z. A. Stein, and M. W. Susser, "Obesity in young men after famine exposure in utero and early infancy," New England Journal of Medicine, vol. 295, no. 7, pp. 349-353, 1976.

[34] T. A. Slotkin, "Fetal nicotine or cocaine exposure: which one is worse?" Journal of Pharmacology and Experimental Therapeutics, vol. 285, no. 3, pp. 931-945, 1998.

[35] H. C. Miller, K. Hassanein, and P. A. Hensleigh, "Fetal growth retardation in relation to maternal smoking and weight gain in pregnancy," American Journal of Obstetrics and Gynecology, vol. 125, no. 1, pp. 55-60, 1976.

[36] N. C. Harvey, J. R. Poole, M. K. Javaid et al., "Parental determinants of neonatal body composition," Journal of Clinical Endocrinology and Metabolism, vol. 92, no. 2, pp. 523-526, 2007.

[37] R. von Kries, G. Bolte, L. Baghi et al., "Parental smoking and childhood obesity-is maternal smoking in pregnancy the critical exposure?" International Journal of Epidemiology, vol. 37, no. 1, pp. 210-216, 2008.

[38] B. Durmuş, C. J. Kruithof, M. H. Gillman et al., "Parental smoking during pregnancy, early growth, and risk of obesity in preschool children: the generation R study," American Journal of Clinical Nutrition, vol. 94, no. 1, pp. 164-171, 2011.
[39] A. Al Mamun, D. A. Lawlor, R. Alati, M. J. O’Callaghan, G. M. Williams, and J. M. Najman, "Does maternal smoking during pregnancy have a direct effect on future offspring obesity? Evidence from a prospective birth cohort study," American Journal of Epidemiology, vol. 164, no. 4, pp. 317-325, 2006.

[40] A. M. Prentice and S. A. Jebb, "Beyond body mass index," Obesity Reviews, vol. 2, no. 3, pp. 141-147, 2001.

[41] S. C. Gorber, M. Tremblay, D. Moher, and B. Gorber, "A comparison of direct vs. self-report measures for assessing height, weight and body mass index: a systematic review," Obesity Reviews, vol. 8, no. 4, pp. 307-326, 2007. 


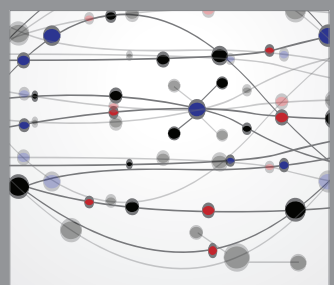

The Scientific World Journal
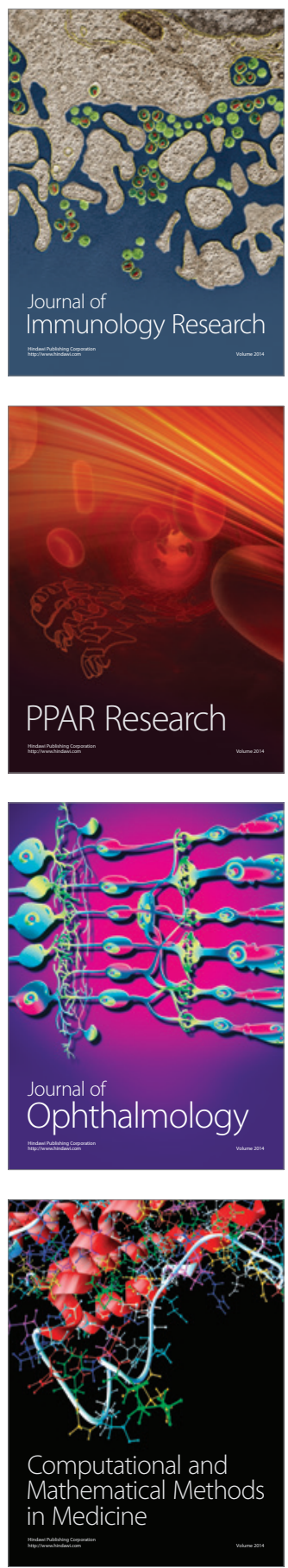

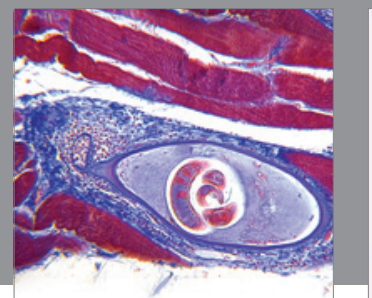

Gastroenterology

Research and Practice
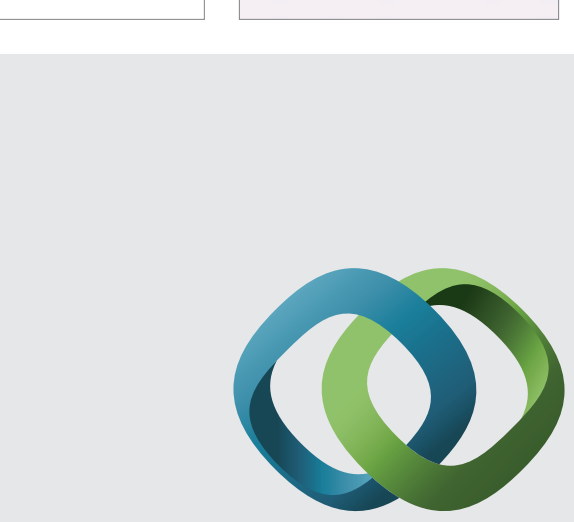

\section{Hindawi}

Submit your manuscripts at

http://www.hindawi.com
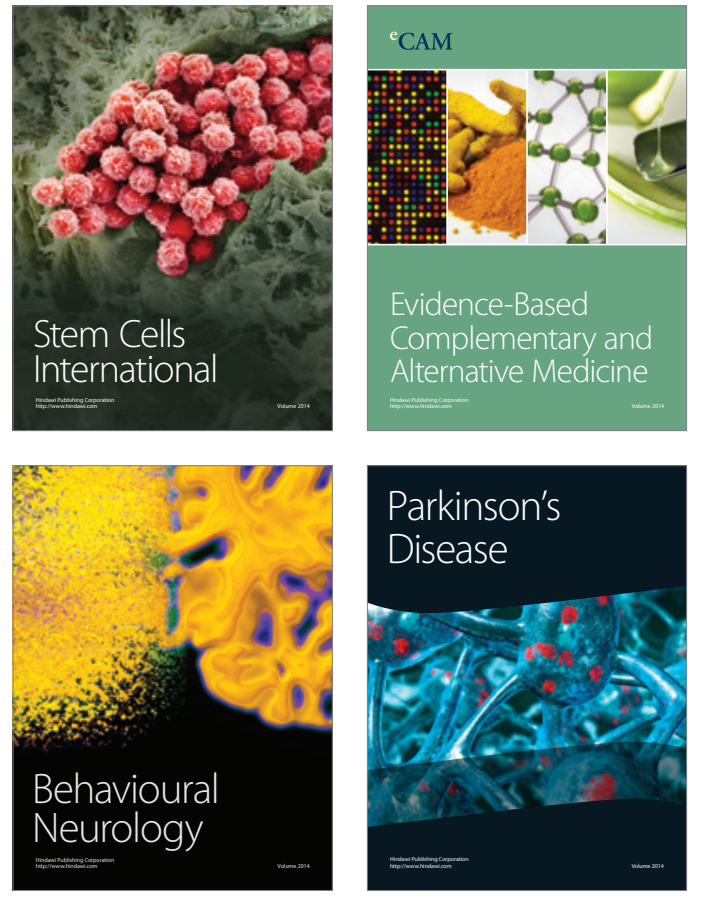
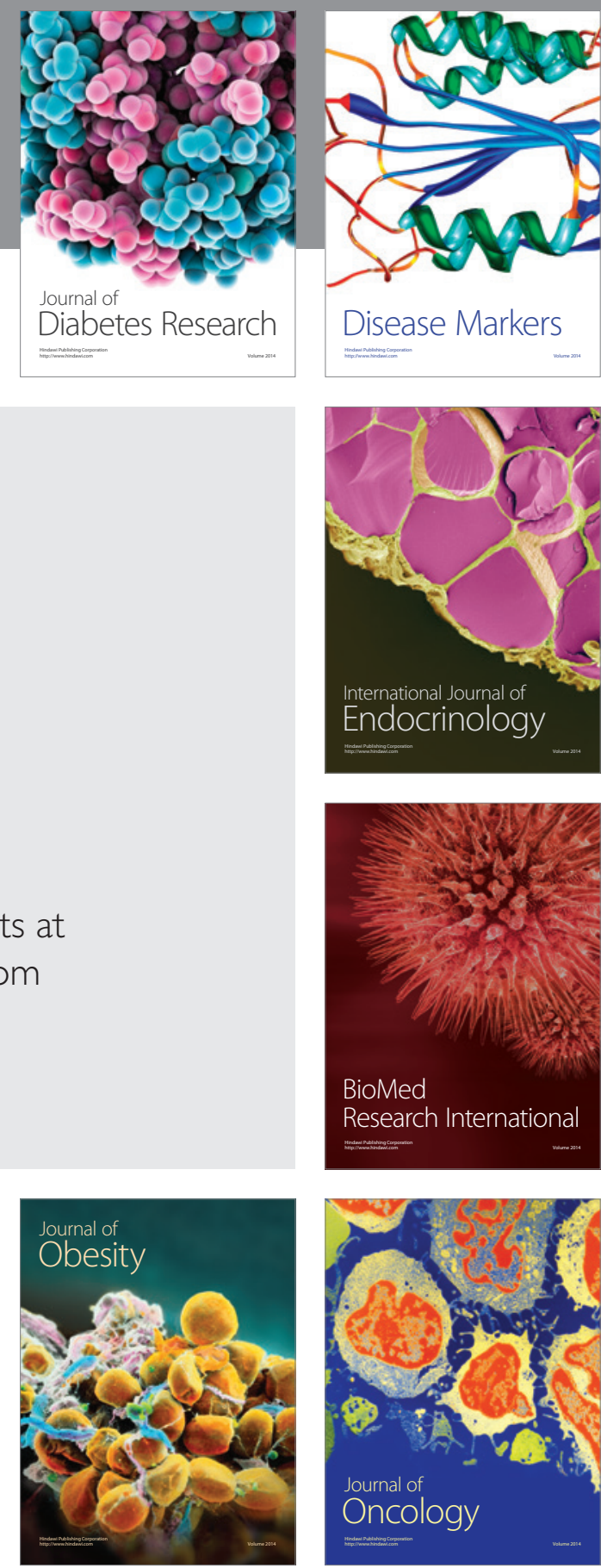

Disease Markers
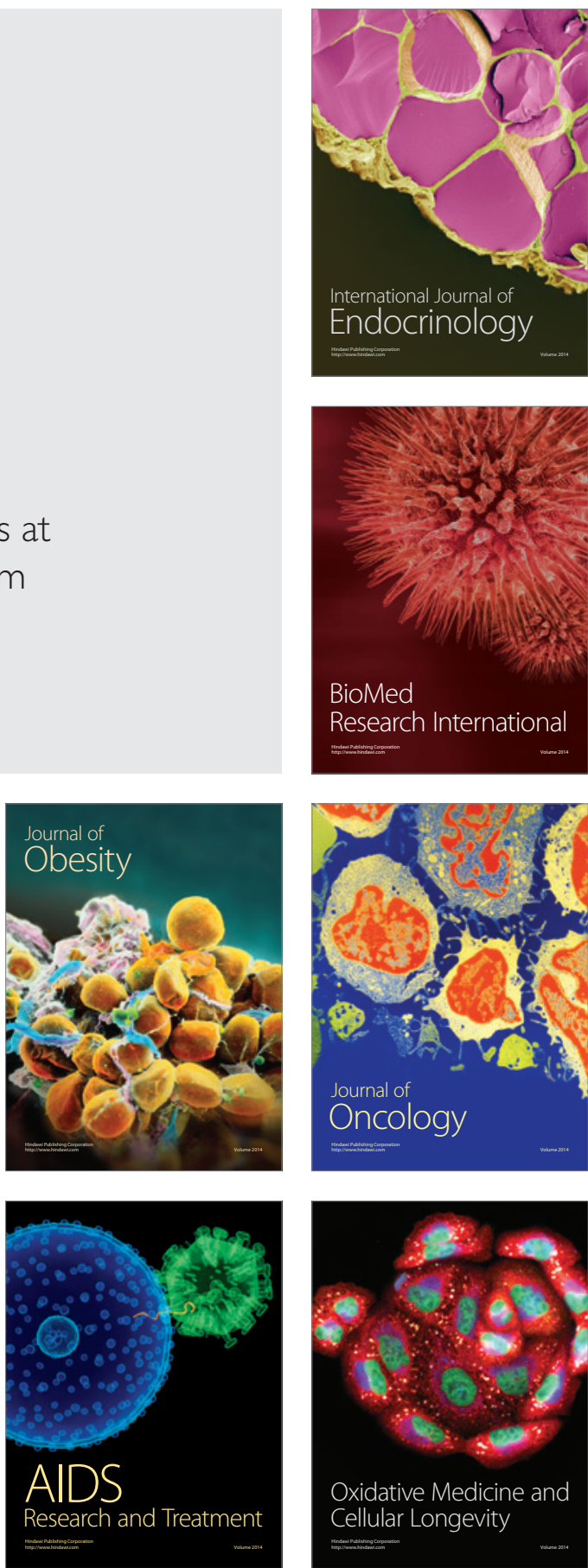